Studia Rossica Gedanensia, 6/2019, 233-240, ISSN 2392-3644 (online), ISSN 2449-6715 (print) DOI: https://doi.org/10.26881/srg.2019.6.19

\title{
О МЕТАЯЗЫКЕ ПЕРЕВОДА
}

\author{
ЛЮДМИЛА В. КУШНИНА
}

\author{
Пермский национальный исследовательский политехнический университет \\ Гуманитарный факультет \\ Кафедра Иностранные языки, лингвистика и перевод \\ Комсомольский пр., 29, 614990, г. Пермь, Россия \\ e-mail: lkushnina@yandex.ru \\ ORCID: https://orcid.org/0000-0003-4360-7243 \\ (получено 3.10.2019; принято )
}

\section{Abstract \\ On the Metalanguage of Translation}

The paper is devoted to the meta-linguistic description of the translation process based on the author's conception of the translation space seen as an interlingual and intercultural interaction of communicants representing different language cultures. The aim of the paper is to clarify the conception's key categories: meaning and its modeling, harmony and disharmony as criteria of assessing the quality of the translation, synergy of sense as the necessary condition for achieving a harmonious translation text. The synergetic approach to the translation process is used as the methodological base. Such an approach leads to the expansion of new meanings into the other culture. The paper provides a metalinguistic description of the translation space components illustrated with examples of translations from French and Italian into English and Russian.

Key words: harmonious translation text, meta language of translation, modeling of the meanings, synergy of meanings, translation space

\section{Резюме}

Статья посвящена метаязыковому описанию процесса перевода, в основу которого положена авторская концепция переводческого пространства, пред- 
ставляющая собой форму бытия межъязыкового и межкультурного взаимодействия коммуникантов, принадлежащих различным лингвокультурам. Целью является освещение ключевых категорий концепции переводческого пространства: смысл и его моделирование, гармония и дисгармония как критерии оценки качества перевода, синергия смыслов как условие достижения гармоничности. В качестве методологии исследования использован синергетический подход к переводу, предполагающий приращение новых смыслов, удовлетворяющих принимающей культуре. Результатом исследования является экспликация метаязыкового описания компонентов переводческого пространства, что проиллюстрировано на материале переводов с французского и итальянского языков на русский и английский языки.

Ключевые слова: гармоничный текст перевода, метаязык перевода, моделирование смыслов, переводческое пространство, синергия смыслов

\section{Введение}

Современная теория перевода вступила в новую фазу своего развития: с одной стороны, исследователи перевода накопили богатейший теоретический и эмпирический материал, требующий серьезного переосмысления и систематизации, а с другой, основные трудности, стоящие перед переводческим сообществом, до сих пор не преодолены, поэтому каждый переводчик остается наедине с собой, самостоятельно достигая вершин мастерства.

Такое утверждение возникло у нас после знакомства с исследованием Н.К. Рябцевой Прикладные проблемы переводоведения: лингвистический аспект, которое обладает, на наш взгляд, свойством фундаментальности по кругу заявленных проблем в связи с междисциплинарным характером их решения (Рябцева 2013). В центре внимания исследователя находится проблема профессионального переводческого мышления, аккумулирующего творческое и стереотипное начала, что требует разработки метаязыка перевода. Между тем автор вынужден признать, что терминология современного отечественного переводоведения недостаточно последовательна и системна, понятийный аппарат нуждается в уточнении ключевых категорий, лингвистические концепции и психологические теории не являются до сих пор прочной основой переводоведения. Достоинство труда Н.К. Рябцевой видится не столько в решении поставленных проблем, сколько в постановке глобальных вопросов мировоззренческого характера, стоящих перед исследователями перевода, поскольку «перевод настолько сложное интеллектуальное и культурное явление, что теория перевода полностью объяснить его специфику не может...» (Рябцева 2013: 211). 


\section{Постановка проблемы и цели исследования}

Задачей настоящей статьи является метаязыковое описание перевода с позиций разрабатываемой нами концепции гармонизации переводческого пространства, разработка которой продолжается более десяти лет (Кушнина 2009).

Начнем с того, что, по замечанию Н.К. Рябцевой в цитируемой выше работе, «...разные теории перевода нередко вводят свои собственные понятия, которые не всегда сопоставимы друг с другом..., разные авторы вкладывают в одни и те же термины разное содержание, т.е. понимают их по-своему...» (Рябцева 2013: 17). Мы придерживаемся мнения о том, что введение новых терминов необходимо для того, чтобы выявить и описать новые закономерности, которые открываются исследователю в ходе разностороннего изучения и пристального наблюдения.

Именно с этой целью мы ввели в научный обиход синергетическую модель перевода - переводческое пространство, которое является для нас ключевым понятием при описании метаязыка перевода. В рамках междисциплинарной парадигмы, полевого подхода к анализу лингвистических явлений, синергетической модели восприятия и порождения текста, а также текстоцентрического и антропоцентрического подходов к процессу перевода, мы пришли к выводу, что перевод есть комплексная система транспонирования множества имплицитных и эксплицитных смыслов из одного языка в другой, из одной культуры в другую. Задача переводчика заключается в воссоздании смысловой системы текста оригинала в тексте перевода, что становится возможным в результате мысленного освоения переводчиком некоей полевой структуры, в которой различаются ядро и периферия. Эта структура представлена переводческим пространством, где в качестве ядра выступает содержание текста, а на периферии находятся поля субъектов переводческой коммуникации (автора, переводчика, реципиента) и текстовые поля (энергетическое и фатическое). Важно подчеркнуть, что каждое поле смыслоцентрично, а смысл текста перевода не является суммой смыслов всех его полей, но результатом их синергии, предполагающей приращение смысла в соответствии с требованиями той культурной традиции, в которую интегрируется текст перевода. В этом нам видится принципиальное отличие переводческого пространства от других моделей перевода. Кроме того, благодаря переводческому пространству ясно выстраиваются отношения между исходным и производным текстами, что позволило нам упорядочить традиционные метапереводческие термины и ввести новые, тем самым выстраивая критерии перевода в следующей иерархической последовательности: гармоничность, эквивалентность, адекватность, дисгармоничность.

Мы выдвинули гипотезу о существовании переводческой гармонии, что является развитием идеи основателя отечественного переводоведения А.В. Федорова, сформулированной следующим образом: «... от определенных единств и единиц оригинала тянутся какие-то нити к переводному произведению, к единствам и единицам, тоже определенно намечаемым; эти нити могут быть прослежены; некоторые же элементы в переводе оказываются как бы ни с чем в оригинале не связанными» (Федоров 2006: 4). Мы предположили, что тради- 
ционные термины «адекватность» и «эквивалентность» характеризуют определенным образом связанные элементы оригинала и перевода. Заметим, что сам А.В. Федоров видел задачу теории перевода в изучении системы «протянутых» и «непротянутых» нитей. Если мы трактуем гармоничный перевод как установление смысловой соразмерности между текстами оригинала и перевода, возникающее в результате синергетического приращения новых смыслов, тем самым мы констатируем, что гармония символизирует «непротянутые» нити. Но и дисгармония, которую мы расцениваем как проявление переводческих ошибок и несоответствий, также отражает «непротянутые» нити, которые ненамеренно возникли при переводе в силу различных объективных и субъективных причин. Разумеется, наряду с гармоничными отношениями, между текстами оригинала и перевода возникают отношения «протянутых нитей», что соответствует адекватному и эквивалентному переводу. Отношения эквивалентности обозначают относительно высокую степень качества перевода, в то время как отношения адекватности - относительно низкую степень качества перевода.

\section{Методология исследования}

Как мы увидим ниже, переводческое пространство является тем интеллектуальным инструментом переводчика, который способствует решению стоящих перед ним профессиональных задач.

Переходя к принципам гармоничного перевода, начнем с категории смысла. В трактовке смысла мы солидарны с позицией И.М. Кобозевой, которая рассматривает его в тесной связи со значением, однако последовательно дифференцируя эти понятия: «...мы наблюдаем отчетливую тенденцию к противопоставлению „значения” как закрепленного за данной единицей языка относительно стабильного во времени и инвариантного содержания, знание которого входит в знание языка, „смыслу” как связанной со словом информации, изменчивой во времени, варьирующей в зависимости от свойств коммуникантов, знание которой не обязательно для знания языка» (Кобозева 2004: 5). Важно, что инвариантное стабильное значение зафиксировано в словаре и эксплицитно выражено в тексте, а варьирующий в зависимости от намерений коммуникантов имплицитный смысл формируется в полях субъектов переводческой коммуникации. При этом каждое поле переводческого пространства наполняется своим смыслом. Это означает, что смыслы субъектов коммуникации не идентичны, но соразмерны друг другу, согласованы друг с другом. Задача переводчика состоит в постижении смыслов автора и в прогнозировании смыслов реципиента, что неотделимо от понимания текста. Ранее решая проблему соотношения «смысл-текст» мы пришли к заключению, что смысл есть лингвистический коррелят понимания текста (Кушнина 2004). С позиций гештальт-синергетического подхода текст предстает как совокупность знаковых единиц, объединенных смысловой связью, возникающих в результате способности текста к транспонированию заключенного в нем смысла на всех уровнях, во всех языках. Эксплицитный, поверхностный уровень смысла проявляется в содержании текста. Имплицитные уровни смысла проявляются в предтексте, контексте, подтексте, 
затексте, интертексте - имплицитных текстовых измерениях, выступающих сущностным свойством текста. Следовательно, текст есть форма существования смысла. Данная трактовка относится как к тексту оригинала, так и перевода, что становится возможным при условии мысленного создания в сознании переводчика особого переводческого пространства, в котором совершается своего рода «жизнь» смысла: его поиск, улавливание, разгадывание, раскрытие, кодирование, декодирование, создание, воссоздание, девербализация, ревербализация, синергия, гармонизация и пр.

Переходим к описанию следующих ключевых понятий разрабатываемой нами концепции, которые составляют метаязык перевода.

Речь идет о существовании множества гетерогенных смыслов, которые наполняют переводческое пространство. Если переводчик извлекает из текста или любого его компонента, начиная со слов и словосочетаний, лишь одно значение или один эксплицитный смысл и, если такой «смыслоусеченный» текст оказывается понятен реципиенту, можно говорить об адекватном переводе, что мы соотносим с буквальным переводом, переводом-подстрочником, учебным переводом. Адекватный перевод мы рассматриваем как начальный уровень анализа в пространстве моделирования смысла.

Обратимся к художественному поэтическому переводу с французского языка на русский. Наше внимание привлекли поэтические тексты М. Карема, перевод которых выполнен М. Ясновым (Maurice 2011: 317)ํ.

\begin{tabular}{|l|l|}
\hline \multicolumn{1}{|c|}{ Bonté } & \multicolumn{1}{c|}{ Доброта } \\
Il faut plus d'une pomme & Яблока не хватит, \\
Pour emplir un panier. & Чтоб украсить стол. \\
Il faut plus d'un pommier & Яблони не хватит, \\
Pour que chante un verger. & Чтобы сад расцвел. \\
Mais il ne faut qu'un homme & А вот человека \\
Pour qu'un peu de bonté & Хватит, чтоб с другим \\
Luise comme une pomme & Честно поделился \\
Que l’on va partager. & Яблоком одним. \\
(Maurice Carême) & (М. Яснов) \\
\hline
\end{tabular}

Данный перевод мы признаем гармоничным: в тексте перевода констатируем наличие лишь ключевых словарных соответствий, в то время как многие лексемы заменены (например: emplir un panier имеет словарное соответствие заполнить корзину, а переведено - украсить стол и др.), но переводчику удалось выразить атмосферу оригинала, передающее намерение доброты, что вызывает полное понимание русскоязычного читателя.

\section{Результаты исследования}

В переводческом пространстве создается такая речевая ситуация, которая обеспечивает синергию смыслов его полей. Синергетический эффект заключа-

1 Maurice C. Рoésies. Морис Карем. Стихотворения. перевод с франц. Михаила Яснова. Maurice Carême Poésies. Москва: «Текст», 2011. 317 c. 
ется в том, что исходный смысл текстовых единиц «наращивается», имеет место осознанное или неосознанное приращение смыслов, в результате чего происходит лингвокультурная адаптация. Предпосылкой такой адаптации являются семантические ассоциации, или коннотации лексем, которые выступают важным типом лексической информации (Кобозева 2004). Ученый подчеркивает специфичность коннотаций для каждого языка. Так, например, по наблюдениям Л.В. Щербы, существует различие между русской лексемой «вода» и французской лексемой «еаu» при образном употреблении слова. Русское понятие воды подчеркивает ее пищевую бесполезность, тогда как французскому этот признак совершенно чужд. Такая непредсказуемость лексем обусловливает необходимость адаптации в условиях переводческого пространства. Еще большие расхождения возникают на уровне значимости - valeur - термин введен Ф. де Соссюром. Значимость соотносится с тем, что данная лексема выражает не только определенное понятие, что имеет универсальный характер и свойственно всем языкам, но и с другими лексемами в рамках конкретного языка, что является лингвоспецифичным. В работах И.М. Кобозевой данное явление получило название семантических корреляций. В рамках переводческого пространства, которое простирается от содержания текста на исходном языке к содержанию текста на языке перевода, поиск семантических корреляций осуществляется, как нам представляется, не столько в процессе поиска смыслов каждого из полей, сколько в процессе синергии смыслов. Это означает, что синергетический эффект можно уподобить установлению оптимальной семантической корреляции в тексте перевода, что является серьезной трудностью для переводчика.

В качестве примера приведем фразу из текста романа А. Иванова в оригинале и в переводе: И лед в моей душе тает - La glace fond dans mon coeur.

Как видим, русское слово «душа», обладающее непредсказуемой системой коннотаций, содержащее в себе понятие «загадочной русской души», при переводе заменяется другой лексемой (coeur - сердие), семантические корреляции которой более понятны носителям французской культуры, так как они воплощают оценку, принятую в данном языковом коллективе. Данный перевод мы также признаем гармоничным.

Мы считаем, что именно синергия смыслов в переводческом пространстве обусловливает их дальнейшую гармонизацию, что приводит к порождению качественного перевода, который становится достоянием другой культуры.

Проанализируем фрагмент бессмертной поэмы Данте в оригинале (итальянский язык) и в переводах на французский, английский, русский языки. Напомним, что Данте начал писать свою поэму в 1305 г., но она была опубликована лишь после смерти автора в 1321 г. Первый опубликованный перевод на французский датируется 1596-1597 гг. Каждая последующая эпоха выдвигала своих переводчиков. Так, например, в ХХ веке было выполнено двадцать переводов на французский язык.

Текст оригинала (итальянский язык):

Era gia l'ora che volge il disio

Ai navicanti e'ntenerisce il core

Lo di c'han detto ai dolchi amici addio. 


\begin{tabular}{|c|c|}
\hline $\begin{array}{l}\text { Перевод на русский язык (А.А. Илюшин) } \\
\text { Настал вечерний час, когда желанья } \\
\text { Влекут отплывших обратно, к любимым, } \\
\text { И вспоминаешь горький час прощанья. }\end{array}$ & $\begin{array}{l}\text { Перевод на английский язык (Henry Wad- } \\
\text { sworth Longfellow) } \\
\text { Twas now the hour that turneth back desire } \\
\text { In those who sail the sea, and melts the heart, } \\
\text { The day they've said to their sweet friends } \\
\text { farewell. }\end{array}$ \\
\hline $\begin{array}{l}\text { Перевод на французский язык (Henri Lon- } \\
\text { gnon) }\end{array}$ & $\begin{array}{l}\text { Перевод на французский язык (Martin Saint- } \\
\text { André) }\end{array}$ \\
\hline $\begin{array}{l}\text { Il était déjà l'heure ou s'emeut de regret } \\
\text { Et s'attendrit le Coeur de ceux qui sont en mer, } \\
\text { Le jour qu'aux doux amis il fallut dire adieu. }\end{array}$ & $\begin{array}{l}\text { Il était déjà l'heure, au coeur attendrissante, } \\
\text { Qui tourne le désir des marins vers le jour } \\
\text { Ou l'adieu des amis berçait leur âme absente. }\end{array}$ \\
\hline
\end{tabular}

Как видим, переводческие решения многочисленны. В каждом конкретном случае в переводческом пространстве формируется индивидуально-образный смысл, с учетом не только индивидуальности переводческой личности, но и «индивидуальности» принимающей культуры. Мы приходим к выводу, что в каждом из представленных переводов в процессе синергии смыслов поля переводчика и фатического поля происходит порождение текста перевода не менее уникального, чем оригинал, благодаря чему великое творение итальянского классика становится достоянием мировой литературы. Такой текст является гармоничным, что подтверждает наше предположение о том, что гармония является вершиной процесса перевода.

\section{Заключение}

Подводя итог проведенному исследованию, подчеркнем значимость метаязыкового описания процесса перевода, что представлено нами в концепции переводческого пространства. Согласно разрабатываемой нами концепции, в качестве важнейших ее составляющих выступают категории гармонии и дисгармонии, которые характеризуют качественный/некачественный переводы. Гармония расценивается нами как аксиологическая доминанта перевода, как некий идеал, к которому стремится переводчик, а дисгармония является результатом неудачного, ошибочного перевода, который также существует в реальной переводческой практике. Мы исследовали моделирование смысла в переводческом пространстве, т.к. считаем, что текст оригинала обладает множеством гетерогенных смыслов, которые необходимо транспонировать переводчику в такое же множество, которое станет неотъемлемым компонентом другой культуры. Этот процесс сопровождается синергией смыслов, что выражается в приращении новых смыслов, приемлемых принимающей культурой. Гармония и синергия смыслов в переводческом пространстве - это процессы, но это и метаязыковые сущности, которые позволяют исследователю проникнуть в сущность перевода, познать его истинное предназначение в культуре отдельной личности и в культуре целой страны. 


\section{Библиография}

Dante Alig'eri (2014). Božestvennaâ komediâ. B per. A. Ilûšina, primečaniâ M.I. Nikola. Moskva: Drofa [Данте Алигвери (2014). Божественная Комедия. В пер. А. Илюшина, примечания М.И. Никола. Москва: Дрофа].

Fedorov, A.V. (2006). O hudožestvennom perevode. Sankt-Peterburg: Izdatel'stvo SPBGU [Федоров, А.В. (2006). О художественном переводе. Санкт-Петербург: Издательство СПбГУ].

Kobozeva, I.M. (2004). Lingvističeskâ̂ semantika. Moskva: Ėditorial URSS [Кобозева, И.М. (2004). Лингвистическая семантика. Москва: Эдиториал УРСС].

Kotûrova, M.P., Baženova, E.A. (2008). Kul'tura naučnoj reči: tekst i ego redaktirovanie. Moskva: Flinta-Nauka [Котюрова, М.П., Баженова, Е.А. (2008). Культура научной речи: текст и его редактирование. Москва: Флинта - Наука].

Kotûrova, M.P. (2010). Stilistika naučnoj reči. Moskva: Akademiâ [Котюрова, М.П. (2010). Стилистика научной речи. Москва: Академия].

Kušnina, L.V. (2004). Vzaimodejstvie âzykov i kul'tur: geštal't-sinergetičeskij podhod. Dissetaciâ na soiskanie učenoj stepeni doktora filologičeskih nauk. Perm': Permskij gosudarstvennyj tehničeskij universitet [Кушнина, Л.В. (2004). Взаимодействие языков и культур: гештальт-синергетический подход. Диссетация на соискание ученой степени доктора филологических наук. Пермь: Пермский государственный технический университет].

Kušnina, L.V., Alikina, E.V. (2010). Garmoniâ v sisteme ocenki kačestva ustnogo perevoda. Vestnik tûmenskogo gosudarstvennogo universiteta: Istoriâ i filologiâ, 1: 141-147 [Кушнина Л.В., Аликина Е.В. (2010). Гармония в системе оценки качества устного перевода. Вестник Тюменского государственного университета: История и филология, 1: 141-147].

Kušnina, L.V. (2013a). Sinergetičeskaâ sistemnost' v perevode $\mathrm{v}$ aspekte meždisciplinarnyh vzaimodejstvij. Stereotipnost'i tvorčestvo. Vyp. 17. Perm': 116-124 [Кушнина, Л.В. (2013). Синергетическая системность в переводе в аспекте междисциплинарных взаимодействий. Стереотипность и творчество. Вып. 17. Пермь: 116-124].

Kušnina, L.V. (20136). Ėlitarnâ̂ rečevaâ ličnost'v perevodčeskom prostranstve russkoj lingvokul'tury. V: Industriâ perevoda. Perm': Permskij nacional'nyj issledovatel'skij politehničeskij universitet: 335-339 [Кушнина, Л.В. (20136). Элитарная речевая личность в переводческом пространстве русской лингвокультуры. В: Индустрия перевода. Пермь: Пермский национальный исследовательский политехнический университет: 335-339].

Kušnina, L.V. (2013в). Perevodovedčeskij diskurs v Rossii: tradicii i sovremennost'. Vestnik PNIPU: Problemy âzykoznaniâ i pedagogiki, 8: 10-16 [Кушнина Л.В. (2013в). Переводоведческий дискурс в России: традиции и современность. Вестник ПНИПУ: Проблемы языкознания и педагогики, 8: 10-16].

Lederer, M. (1994). La traduction aujourd'hui. Paris: Hachette.

Maurice, C. (2011). Poésies = Moris, K. Stihotvoreniâ. Perevod s franc. M. Âsnova. Seriâ Bilingva. Moskva: Tekst [Maurice, C. (2011). Poésies = Морис, К. Стихотворения. Перевод с франц. М. Яснова. Серия Билингва. Москва: Текст].

Râbceva, N.K. (2013). Prikladnye problemy perevodovedeniâ: lingvističeskij aspekt. Moskva: Flinta [Рябцева, Н.К. (2013). Прикладные проблемы переводоведения: лингвистический аспект. Москва: Флинта]. 